\title{
KULIT JERUK UNTUK AROMATERAPI DAN PENGARUHNYA TERHADAP PENURUNAN NYERI HAID
}

\author{
1)Ari Christiana, ${ }^{2)}$ Mizam Ari K. \\ STIKES WidyagamaHusada \\ 1)ch_ari@ymail.com ${ }^{1}$ \\ 2)mizam_ari@yahoo.com²
}

\begin{abstract}
The peel of Mandarin orange contains essential oils that are known to be able to stabilize the nervous system that can cause a calming effect for those who inhale it. Astiri oil contained in the mandarin oranges includeslonalol, limonene, linalil, and terpinol which function as a sedative to produce relax and peaceful feeling. The purpose of this study was to find out the function of citrus aromatherapy in reducing the intensity of menstrual pain. In this study, the intensity of menstrual pain was measured before and after the treatment. The treatment itself was done to 30 respondents by giving the mandarin orange peel aromatherapy through bowling technique. The pain intensity after the treatment was measured using Visual Analogue Scale (VAS) and the results showed that seven respondents did not experience pain after the treatment, 19 respondents experienced mild pain and four respondents did moderate pain. After analyzing the data using paired T-test sample, it was found that the significance level was $0.000<\alpha$ 0.05. So it could be concluded that there were differences in menstrual pain scale before and after the treatment. The findings of this study showed not only the level of menstrual pain declined after being given the Mandarin Orange peel aromatherapy, but the feeling of the respondents during the period also became more relaxed.
\end{abstract}

Keywords: Aromatherapy Orange Peel, Dysmenorrhea 


\section{Abstrak}

Kulitjeruk mandarin diketahui mengandung minyak atsiri yang bergunauntukmenstabilkansystemsarafsehinggadapatmenimbulkanefektenangbagi yang menghirupnya. Kandunganminyakastiripadajeruk mandarin yaknilonalol, limonen, linalil, danterpinol yang memilikifungsisebagipenenang, rileksdandamai.Pada penelitian ini ingin diketahui fungsi aromaterapi jeruk dalam menurunkan intensitas nyeri haid.Metode penelitian dengan cara mengukur intensitas nyeri haid sebelum diberikan perlakuan kemudian selama periode menstruasi responden diberikan aromaterapi kulit jeruk mandarin melalui teknik bowling lalu intensitas nyeri diukur kembali menggunakan VAS (Visual Analog Scale).Hasil yang dicapai pada penelitian ini adalah dari 30 responden yang telah diberikan aromaterapi, 7 responden tidak mengalami nyeri, 19 responden mengalami nyeri ringan dan 4 responden mengalami nyeri sedang. Setelah dilakukan analisis data menggunakan uji T sampel berpasangan didapatkan tingkat signifikasi 0,000 $<\alpha 0,05$. Sehingga dapat disimpulkan bahwa terdapat perbedaan skala nyeri haid sebelum perlakuan dan sesudah perlakuan.Kesimpulan dari penelitian ini adalah terjadi penurunan tingkat nyeri haid dari responden setelah diberikan aromaterapi jeruk, dan dari hasil wawancara responden mengatakan selain nyeri berkurang responden juga merasa lebih rileks.

Kata Kunci : Aromaterapi Kulit Jeruk, Nyeri Haid

\section{PENDAHULUAN}

Seorang remaja putri yang telah memasuki masa pubertas akan mengalami siklus menstruasi tiap bulannya (Riyanto, 2001). Siklus menstruasi ini akan menyebabkan timbulnya rasa sakit atau nyeri di daerah abdomen (Junizar, et al., 2001). Dismenorea atau nyeri haid yang dirasakan bersifat subjektif. Dismenorea yang sering terjadi pada remaja adalah dismenorea primer. Remaja putri akan lebih sering merasakan sakit akibat dismenorea primer karena siklus hormonal yang dialami belum begitu stabil, dan remaja putri belum sering mengalami kontraksi uterus seperti wanita dewasa muda. Dismenorea primer ini akan sangat mengganggu konsentrasi dan aktivitas para remaja putri (Junizar, et al., 2001).

Tidak ada angka pasti mengenai jumlah penderita nyeri haid di Indonesia. Di Jakarta, dismenorea primer pada remaja masih sekitar $83,5 \%$ pada tahun 2001
(Riyanto, 2001). Penelitian lain, di dunia dikatakan prevalensi dismenorea primer masih mencapai angka 90\% pada remaja putri yang aktif (Holder, et al., 2009). Sekitar 15\% gadis remaja dilaporkan mengalami dismenore berat dan merupakan penyebab tertinggi para gadis remaja tidak hadir di sekolahnya di Amerika Serikat. Lebih lanjut dalam sebuah studi longitudinal yang dilakukan di Swedia melaporkan dismenorea terjadi pada 90\% wanita yang berusia kurang dari 19 tahun dan $67 \%$ wanita yang berusia 24 tahun (French, 2005). di Indonesia angka kejadian dismenore adalah sekitar 54,89\%(Proverawati dan Misaroh, 2009). Distraksi adalah mengalihkan perhatian klien ke hal lain yang dapat menurunkan kewaspadaan terhadap nyeri, bahkan meningkatkan toleransi terhadap nyeri (Tamsuri, 2007). Ada berbagai cara atau metode yang digunakan untuk mengalihkan perhatian terhadap rasa nyeri yang dialaminya, antara lain: distraksi 
visual, distraksi pendengaran, distraksi pernafasan, tehnik pernafasan, imajinasi terbimbing. Salah satunya dengan menggunakan aromaterapi, untuk merangsang tubuh agar dapat merasa nyaman dengan aroma yang menyejukkan (Bakir, 2009). Aromaterapi yang bisa dipergunakan diantaranya jeruk. Kulit jeruk mandarin diketahui mengandung aroma yang khas dan bisa digunakan untuk pengobatan. Dalam kaitannya dengan kesehatan minyak astiri yang tergandung dalam kulit jeruk berguna untuk menstabilkan sistem saraf sehingga dapat menimbulkan efek tenang bagi yang menghirupnya. Kandungan minyak astiri pada jeruk mandarin yakni lonalol, limonen, linalil, dan terpinol yang memiliki fungsi sebagi penenang, rileks dan damai. (Susilo, 2007).

Dari hasil sebuah penelitian kepada 40 wanita diketahui bahwa aroma jeruk manis efektif sebagai penenang (J Altern Complement Med.2012). Selain itu dari penelitian lain disebutkan bahwa minyak essensial jeruk efektif untuk mengurangi nyeri lutut pada orang tua (Complement Ther Med. 2008). Penelitian ini bertujuan untuk membuktikan bahwa kandungan limonen dalam jeruk dapat menurunkan intensitas nyeri haid pada remaja.

\section{METODE PENELITIAN}

Tahap pelaksanaan penelitian ini adalah responden sebelumnya diukur intensitas nyeri haidnya kemudian selama periode menstruasi responden diberikan aromaterapi kulit jeruk dengan cara mengisi sebuah mangkuk kecil dengan air panas dan menambahkan minyak esensial kulit jeruk mandarin ke dalamnya. Lalu ditempatkan disudut kamar agar aromaterapi tersebut bisa terhirup oleh responden. Intensitas nyeri haid diukur setiap hari selama periode menstruasi dengan menggunakan VAS (Visual Analog Scale).

\section{HASIL PENELITIAN}

Hasil yang dicapai pada penelitian ini adalah :

1. Dari 30 responden yang telah diberikan aromaterapi, 7 orang tidak mengalami nyeri haid, dan 19 responden mengalami nyeri ringan dan 4 responden mengalami nyeri sedang.

2. analisis data menggunakan uji $\mathrm{T}$ sampel berpasangan didapatkan tingkat signifikasi $0,000<\alpha$ 0,05. Sehingga dapat disimpulkan bahwa terdapat perbedaan skala nyeri haid sebelum perlakuan dan sesudah perlakuan.

\section{KESIMPULAN}

Setelah diberikan aromaterapi hasil yang dicapai pada penelitian ini adalah dari 30 responden yang telah diberikan aromaterapi, 7 responden tidak mengalami nyeri ringan dan 4 responden mengalami nyeri sedang. Setelah data didapatkan dari seluruh responden yaitu 30 responden, maka dilakukan analisis data menggunakan uji $\mathrm{T}$ sampel berpasangan. Hasil yang didapatkan dari hasil uji $\mathrm{T}$ dari penelitian ini adalah tingkat signifikasi sebesar 0,000. Sehingga dapat disimpulkan bahwa terdapat perbedaan skala nyeri haid sebelum dan sesudah pemberian aromaterapi. 
DAFTAR PUSTAKA

Agusta, Andria. 2008. Aromaterapy, Cara Sehat Dengan Wewangian Alami. Jakarta : Penebar Swadaya.

Bakir, Suyoto. 2000. Aroma Therapy. Tangerang : Kharisma Publishing Group. Complement Ther Med. 2008 Jun;16(3):131-8. doi: $\quad$ 10.1016/j.ctim.2007.12.003. Epub 2008 Mar 4.An experimental study on the effectiveness of massage with aromatic ginger and orange essential oil for moderate-tosevere knee pain among the elderly in Hong Kong.

Dalimartha, Setiawan. 2006. Atlas Tumbuhan Obat Indonesia. Jakarta : Wisma Hijau. French L. 2005. Dysmenorrhea. American Family Physician. 71 (2): 285- 91.M. 2009.

Dysmenorrhea.

http://emedicine.medscape.com/a rtic le/795677-overview

J Altern Complement Med. 2012 Aug;18(8):798-804.doi:

10.1089/acm.2011.0551. Epub 2012 Jul 31. Effect of sweet orange aroma on experimental anxiety in humans.

Primadiati, Rachmi. 2008. Aromaterapi jeruk. Jakarta : Gramedia Pustaka Utama.

Potter 2005. Buku Ajar Fundamental Keperawatan;Konsep, Proses dan Praktik Vol.2. Jakarta : EGC.

Proverawati \& Misaroh, 2009. http:// herbal - obat. Blogspot.Com/ search/ label/ Diagnosa Nyeri Haid, diunduh pada tanggal 2 Oktober 2013

Riyanto H. 2001. Nyeri Haid pada Remaja. http://www.yastroki.or.id/read.p

hp?i d=190. (3 Oktober 2013).

Simanjuntak P. 2008. Gangguan Haid dan Siklusnya. In: Winkjosastro H., Saifuddin A.B., Rachimhadhi T. (eds.). Ilmu Kandungan. 2nd ed. Jakarta: PT Bina Pustaka Sarwono Prawirohardjo

Unizar G., Sulianingsih, and Widya K.D. 2001. Pengobatan Dismenore secara Akupuntur. Cermin Dunia Kedokteran. 